\title{
What do adult squash players think about protective eyewear?
}

\author{
Caroline Finch, Paul Vear
}

\begin{abstract}
Objective-To determine the attitudes of adult squash players towards protective eyewear.

Methods-A survey of 197 competition and social squash players from seven squash centres in the outer eastern suburbs of Melbourne, Australia was conducted in September to October 1995. Information about participation in squash, previous injuries, use of protective eyewear, barriers towards eyewear use, and attitudes towards protective eyewear was obtained by a self report questionnaire.
\end{abstract}

Results-Squash is a popular sport in Australia. Of the players surveyed, $6 \%$ played in junior competitions, $67 \%$ in senior competitions, and $27 \%$ were social players. Most had been playing for more than ten years. Some 15\% of players had previously suffered an eye injury, most commonly caused by a racquet. Less than $10 \%$ of players reported that they wore protective eyewear when they played squash, and $35 \%$ of these wore prescriptive lenses which they considered to be protective. The major reason for not wearing protective eyewear was the perception that it was unnecessary. Poor vision and a lack of comfort were also stated as reasons by a significant number of players. More than half $(57 \%)$ of the respondents agreed that more players should wear protective eyewear, yet only $16 \%$ thought it should be compulsory for all players. There was considerable support for protective eyewear use by junior players, however.

Conclusions-The rate of protective eyewear use is low among competition and social squash players in Melbourne. The major areas that need to be addressed are the ignorance of the need for protective eyewear among social and experienced players and the mistaken belief that prescription lenses provide adequate protection on a squash court.

(Br F Sports Med 1998;32:155-161)

Keywords: squash; protective eyewear; attitudes; eye injuries

Federation, Burwood

P Vear

Correspondence to: Dr C F Finch, Senior Lecturer, School of Human Movement, Deakin University, 221 Burwood Highway, Burwood, Victoria 3125, Australia.

Accepted for publication 17 December 1997 players in Australia with 300000 social and competitive players participating on a weekly basis. About 30000 court hours are played
Squash is one of the most popular sports played in Australia. The 900 squash centres provide a total of 5000 squash courts around Australia. There are 1.25 million squash each day with an annual total of about 9 million court hours.

Squash is a highly competitive and enjoyable sport, played in a confined area at great speed. The ball is played at various angles, the racquet stroke requires a wide arc at speed, and there is a need to face towards the back of the court on occasion. ${ }^{1}$ It is easy to see why there is a risk of being hit by the ball or racquet.

Although a small target compared with the rest of the body, eyes are the frequent site of injury in squash with catastrophic results. ${ }^{1-3}$ The eyes are enclosed in orbits within bony cavities, in the front of the head. These sockets give considerable protection against injury, except from blows from the front, which can produce serious injury. ${ }^{1}$

The squash ball is of perfect size and malleability to enter the orbit and consequently push the eyeball backwards resulting in a compression injury to the globe. ${ }^{2}$ A small squash ball has greater propensity than a racquet to cause serious injuries that warrant medical attention from ophthalmic specialists or hospital consultations. ${ }^{2}$ In contrast, racquet injuries are often more superficial lid and adnexal injuries and corneal abrasions. ${ }^{2}$ Both racquets and balls can cause a wide spectrum of serious and catastrophic injuries, including hyphaema (bleeding into the anterior part of the eye), lid haemorrhages or lacerations, corneal abrasions, iritis, and vitreous or retinal haemorrhages. ${ }^{2}{ }^{3}$ Occasionally, there is complete loss of the eye.

With recreational and sporting activity becoming increasingly popular as a means of relaxation, social enjoyment, and general fitness, the incidence of sporting injuries has also increased. This is particularly so for sports related eye injuries. The first comprehensive survey of eye injuries was conducted by Garrow in $1923,{ }^{4}$ who found that, of 1000 patients admitted to hospital over a five year period, only $0.7 \%$ were related to a sporting injury. ${ }^{4}$ Today, sports related eye injuries in similar studies range from 5 to $42 \%$ of all eye trauma. ${ }^{25}$ A recent Australian study found that sports injuries comprised only $5 \%$ of all eye trauma. ${ }^{2}$ However, they account for a disproportionately high ocular morbidity, representing $22 \%$ of hospital admissions at a large eye and ear hospital. ${ }^{2}$ Sporting activities do not cause a large number of eye injuries compared with work, for instance, but sports injuries are more likely to be serious. ${ }^{1}$

Attention was first drawn to the specific problem of squash related eye injuries by North ${ }^{6}$ and Ingram and Lewkonia. ${ }^{7}$ Since then numerous other reports have followed. ${ }^{2}$ 8-19 $^{\text {Squash has }}$ consequently been established as a major 
Table 1 Summary of the relative frequency of sports related eye trauma according to the sport undertaken

\begin{tabular}{|c|c|c|c|c|c|c|}
\hline Sport & $\begin{array}{l}\text { Barrell et al }{ }^{8} \text { : } \\
\text { Casualty department } \\
\text { presentations in } \\
\text { Southampton, } 1981\end{array}$ & $\begin{array}{l}\text { Gregory } y^{12} \text { : All sports } \\
\text { injuries presenting to the } \\
\text { Sussex Eye Hospital, } \\
\text { between Oct } 1982 \text { and } \\
\text { Mar } 1984\end{array}$ & $\begin{array}{l}\text { MacEwen }{ }^{16}: \text { All sports } \\
\text { injuries presenting to the } \\
\text { Glasgow E Western Eye } \\
\text { Hospital, between fan } \\
1985 \text { and Fune } 1986\end{array}$ & $\begin{array}{l}\text { Fones }^{20}: \text { All sports } \\
\text { injuries presenting to } \\
\text { the Manchester Royal } \\
\text { Eye Hospital, Fan } \\
1987-D e c 1987\end{array}$ & $\begin{array}{l}\text { MacEwen }{ }^{5} \text { : } \\
\text { Casualty department } \\
\text { presentations in } \\
\text { Glasgow, } 1989\end{array}$ & $\begin{array}{l}\text { Fong }^{2} \text { : All sports injuries } \\
\text { presenting to the Royal } \\
\text { Victorian Eye E Ear } \\
\text { Hospital, from Nov } \\
1989 \text { to Oct } 1991\end{array}$ \\
\hline Squash & 49 & 26 & 8 & 23 & 10 & 17 \\
\hline Badminton & 20 & 17 & 7 & 19 & 7 & 3 \\
\hline Football (all codes) & 19 & 21 & 45 & 33 & 42 & 16 \\
\hline Rugby & - & 7 & 10 & 4 & 5 & - \\
\hline Tennis & 8 & 12 & 3 & 8 & - & 8 \\
\hline Netball/basketball & - & - & - & - & - & 12 \\
\hline Cricket & - & - & 2 & 4 & - & 14 \\
\hline Other & 4 & 17 & 25 & 7 & 36 & 30 \\
\hline Total & 100 & 100 & 100 & 100 & 100 & 100 \\
\hline
\end{tabular}

Values represent the proportion of all cases associated with each sport.

contributor to the incidence of sports related eye trauma. Table 1 summarises the studies that have provided data about sports related eye injuries according to the sport undertaken at the time of injury. Squash has been found to contribute from 8 to $49 \%$ of all sports related eye injuries. In three of the studies summarised in table 1 , squash was found to be the major single sport contributing to all sports related eye injuries. ${ }^{2812}$

In comparing the incidence of eye injury across sports, it is also important to consider the number of participants. This factor was accounted for by $\mathrm{Fong}^{2}$, for example, who reported the incidence of squash related eye injuries in Australia to be 64 per 100000 participants, ranking it second only to football (86 per 100000$)$. In terms of playing hours, the incidence of eye injury in Australia is reported to be 17.5 per 100000 playing hours. ${ }^{13}$ Reports from Canada, the United States, the United Kingdom, and New Zealand have produced incidence rates ranging from 5.2 to 33.3 per 100000 playing sessions. $^{38132324}$

Fong $^{2}$ reported that $62 \%$ of eye injuries in squash were produced by the ball. This is similar to other reports from ophthalmologists and hospital records. ${ }^{8121625}$ Community surveys have identified the racquet as the more common causative factor. ${ }^{13}{ }^{26}$ This difference is not surprising, since it reflects the source of the injury information. Hits from a squash ball can cause more severe damage to the eye than strikes from a racquet, and these serious injuries are more likely to be identified in any study of eye injuries leading to ophthalmologist or hospital visits. ${ }^{21-13}$ In community surveys, a broader range of injuries, with varying severity, are likely to be identified. In contrast, other studies have found that racquets cause a disproportionate proportion of severe eye injuries to squash players. ${ }^{71415}$

Despite the inherent dangers associated with participating in squash, squash players rarely wear adequate protective eyewear. ${ }^{21}$ Genovese et $a l^{13}$ reported that only $8 \%$ of the squash players they surveyed in Perth wore eye protection while playing. Inadequate use of protective eyewear has also been reported in other similar studies. $^{2132122}$

Despite epidemiological and anecdotal evidence about the incidence of eye injury, along with encouragement from key sports medicine and squash organisations, the use of protective eyewear by squash players remains low. One of the major barriers towards the use of protective eyewear is the negative attitudes that some players have towards it. Attitudinal surveys in Australia and the United Kingdom have identified key barriers to include lack of comfort, obstructed vision, expense, and poor appearance..$^{1321}$ On the other hand, in Canada, where protective eyewear use is widespread, some players have reported that they feel incompletely equipped without it. ${ }^{22}$ Attention to these attitudes is an important component of strategies to promote eyewear use..$^{2129}$

The purpose of this paper is to present the results of a survey of the attitudes of adult squash players in Melbourne towards protective eyewear. The survey was conducted in July-October 1995 before the start of promotional activities aimed at increasing protective eyewear use. The outcomes of these promotional activities will be reported elsewhere.

\section{Methods}

The outer eastern region of Melbourne was chosen as the focus of this survey because a large proportion of Victorian adult competition squash players participate at centres in this area. Furthermore, centres in this region have a large base of junior squash players. If junior players are to be encouraged to wear protective eyewear, then it is important that they see their role models and adult players also wearing the same eyewear.

Throughout the outer eastern region of Melbourne there are 24 squash venues, of which seven provide over $50 \%$ of the total competitive players in this region. These seven centres (Box Hill, Wattle Park, Wantirna, Upwey, Knox Bayswater, Croydon, and Eastland) were all approached to participate in the study. A major incentive to the centres for participating in the project was the fact that the programme would help market the protective eyewear within the centre to all competition and social players. This could encourage players to purchase the eyewear, which in turn would provide profits to the venue operators. Furthermore, the venue operators would be seen by the players to be making a conscious effort to increase their awareness of the advantages of wearing protective eyewear and promoting safety. No financial incentives were provided to the players or centres to encourage high response rates in this survey. 
Each of the seven centres approached agreed to participate in this study and to distribute copies of an attitudinal survey to its pennant and social players.

A self report questionnaire was developed to collect information about levels of participation in squash and attitudes, behaviours, and knowledge about protective eyewear for squash. Closed questions with specified options were generally used to facilitate analysis. However, open ended questions were also used to explore fully attitudes and behaviours. For comparison purposes, some of the attitudinal questions were the same as those posed in a survey of pennant players in Perth, Australia in $1989 .{ }^{13}$

The questionnaire collected information about:

(a) basic demographics - for example, age, sex, occupation;

(b) participation in squash-for example, number of hours played per week, total years of squash played, standard of competition or social play;

(c) self reported previous injury-for example, eye injury or other injury, cause of the injury;

(d) use of protective eyewear-for example, frequency, type;

(e) attitudes towards protective eyewear-for example, reasons for wearing or not wearing;

(f) knowledge about protective eyewear-for example, where it is available, its use for preventing injuries.

It was intended that a survey form would be distributed to every squash player who came into one of the seven venues. A programme coordinator was appointed to take responsibility for distributing the surveys to club members and social players. The venue operators were also encouraged to play a major role in the distribution of the survey forms. The questionnaires were distributed to centres in July 1995, and responses were collected between September and October 1995. A total of 350 questionnaires were circulated, with 50 being given to each of the seven centre coordinators.

Players were provided with a plain language letter explaining the study, before they agreed to complete the questionnaire. Completion of the form by the squash players was entirely voluntary. Players participating in the survey, and who agreed to participate in a trial of protective eyewear, were advised that they would be provided with free eyewear to try out for a three month period. At the conclusion of this trial period they would be able to purchase the eyewear at a discounted rate. The results of this trial will be reported elsewhere.

The number of registered members or social players at the seven participating centres was estimated to be 1970 . Completed survey forms were received from 197 players, corresponding to a $10 \%$ sample of all registered/social players at these clubs. In individual clubs, the response rate varied from 3 to $50 \%$. It is recognised that the sampling process used in this study would not necessarily lead to squash players representative of each venue, particularly when there was a low response rate. However, it was considered that valuable information could still be obtained from these adult squash players about current attitudes towards protective eyewear.

All attitudinal data were precoded before computer entry into a PC. Descriptive statistical analyses were performed with the SPSSWIN statistical package. Either the $Z$ test for proportions or $\chi^{2}$ was used to compare proportions.

\section{Results}

Overall, 197 of the 350 distributed survey forms were completed. This corresponds to a response rate of $56 \%$. Reasons for nonresponse could not be determined.

\section{DEMOGRAPHICS}

Of the 197 players who responded to the survey, most were aged between 24 and 44 $(40 \%)$ or between 15 and $22(35 \%)$; nine respondents $(5 \%)$ were aged under 14 years and the remainder $(20 \%)$ were over 44 . There were nearly twice as many male $(65 \%)$ as female $(35 \%)$ respondents, reflecting the participation ratios in the game.

Most respondents were from professional occupations; $26 \%$ were classified as professionals, $10 \%$ as para-professionals, $14 \%$ as managers or administrators, $13 \%$ were tradespersons, and $18 \%$ of the sample were students.

PARTICIPATION IN SQUASH

Most (61\%) of the respondents had been playing squash for over ten years. Almost equal numbers had played the game for less than one year, between two and four years and for between five and ten years. Of the 196 people who reported their level of play, $11(6 \%)$ played in junior competitions and $131(67 \%)$ in senior competitions. The competitive players were generally involved in pennant competition, which is regular, usually weekly, interclub league competitions. Almost $30 \%$ of respondents said that they played social squash.

More than half of the respondents (53\%) played squash for two to four hours a week. A further $24 \%$ played squash for only one hour a week, and the remainder were equally divided between five to ten hours a week and more than ten hours.

HISTORY OF INJURY

Thirty squash players-that is, $15 \%$ of the sample-reported that they had suffered an eye injury while playing squash. Of these, the most frequently reported cause was the racquet $(\mathrm{n}=$ $23,77 \%)$, followed by the ball in seven (23\%) cases. Only $9 \%$ of the social players reported previous eye injury, compared with $17 \%$ of the competition players (juniors and seniors combined). This difference was not statistically significant.

Some $60 \%$ of the respondents reported that they had incurred an injury to another part of the body while playing squash. Some respondents listed more than one injury, and of the 109 respondents who gave this information, the most commonly injured body regions were the leg $(30 \%)$, head/face $(20 \%)$, ankle $(18 \%)$, and 
Table 2 Major reasons why adult squash players choose not to wear protective eyewear

\begin{tabular}{|c|c|c|c|c|c|}
\hline Reason & $\begin{array}{l}\text { Proportion of all players } \\
\text { who do not wear protective } \\
\text { eyewear }(\%)(n=172)\end{array}$ & $\begin{array}{l}\text { Funior competition } \\
\text { players }(\%)(n=8)\end{array}$ & $\begin{array}{l}\text { Senior competition } \\
\text { players }(\%)(n=114)\end{array}$ & $\begin{array}{l}\text { Social players } \\
(\%)(n=54)\end{array}$ & $\begin{array}{l}p \text { value of the comparison } \\
\text { between senior competition } \\
\text { and social players }\end{array}$ \\
\hline I do not need to/they are not necessary & 3 & 13 & 16 & 37 & $<0.01$ \\
\hline $\begin{array}{l}\text { I have no particular reason/I don't know/ } \\
\text { I've never thought about it }\end{array}$ & 18 & 13 & 17 & 18 & ns \\
\hline They are too uncomfortable & 13 & 25 & 15 & 9 & ns \\
\hline They affect my vision & 12 & 0 & 16 & 2 & $<0.01$ \\
\hline I don't like them & 8 & 0 & 9 & 4 & ns \\
\hline I have never worn them & 8 & 13 & 9 & 7 & ns \\
\hline I am experienced and not at risk of injury & 7 & 0 & 11 & 5 & ns \\
\hline
\end{tabular}

ns, Not significant.

back $(17 \%)$. Other body parts injured included the arm/hand, nose, neck, shoulder, chest, foot, and knee. Reported injuries were significantly more frequent in competition players than social players $(73 \%$ v 27\%) $(\mathrm{p}<0.001)$.

Of the 95 respondents who provided information about the cause of the injury, $48 \%$ stated that it was caused by the racquet, $37 \%$ by a fall, $25 \%$ by the ball, $24 \%$ by a collision with the court wall, and $12 \%$ by a collision with their opponent. A comparison of the proportions of reported eye injury and "other" injury involving the racquet $(77 \% v 48 \%)$ suggests that racquet strikes are a much more significant factor in the cause of eye injuries than injuries to other parts of the body $(\mathrm{p}<0.01)$.

\section{PROTECTIVE EYEWEAR USE}

Seventeen $(9 \%)$ respondents reported that they wore protective eyewear when playing squash; only one of these was a social player. Of these, six claimed their prescription lenses were protective eyewear, three wore "Leader" eyewear, and the remainder either wore industrial spectacles or did not specify the type they wore.

\section{BARRIERS TO PROTECTIVE EYEWEAR}

A number of reasons for wearing protective eyewear were stated by the 17 players who said they wore it and some gave more than one response. The most common response was "I don't want an injury" ( $n=11)$ followed by "I don't want to be blinded" $(\mathrm{n}=7)$ and "I need lenses to see" $(n=6)$.

Reasons for not wearing protective eyewear were given by 172 of the 180 players who did not wear it. Table 2 lists the major reasons. Almost a quarter of this group did not wear protective eyewear because they considered it unnecessary or believed that they did not need to. More than twice as many social squash players as those who played in competitions $(\mathrm{p}<0.01)$ gave this as a reason. A significant proportion (18\%) could give no particular reason for not wearing protective eyewear. Other reasons included "it is too restrictive" ( $6 \%$ of cases) and "they are not fashionable" (7\%). Competition players were significantly more likely to report that eyewear affected their vision than social players $(p<0.01)$. They were also more likely to report that it was uncomfortable, but this was not statistically significant.

\section{KNOWLEDGE ABOUT AVAILABILITY OF PROTECTIVE} EYEWEAR

More than half $(60 \%)$ of the survey respondents stated that protective eyewear could be obtained from squash centres or clubs. Other places suggested were sports stores (33\%), an optometrist $(6 \%)$, and an industrial safety store (1\%). Over $20 \%$ did not know where protective eyewear could be obtained.

ATTITUDES TOWARDS PROTECTIVE EYEWEAR

Table 3 summarises the respondents' attitudes towards protective eyewear. The first four of these attitudes are the same as those explored by Genovese et al. ${ }^{13}$ The numbers in parentheses represent the responses found by Genovese and co-workers in their study of pennant players in Perth in 1989 for comparative purposes. There were no significant differences in attitudes between competition and social players.

While more than half of the respondents (57\%) agreed or strongly agreed that more players should wear protective eyewear, only $16 \%$ thought that it should be made compulsory for all players. Interestingly, only $8 \%$ of players said that they would stop playing squash if protective eyewear were made compulsory. From a comparison of the results from this survey with those from Genovese et al, ${ }^{13}$ it is apparent that general attitudes towards compulsory eyewear in Australia have not changed much since 1990.

Table 3 Attitudes towards protective eyewear in pennant and social squash players in Melbourne, 1995, compared with those of pennant players in Perth in 1989 (given in parentheses)

\begin{tabular}{|c|c|c|c|c|c|c|}
\hline \multirow[b]{2}{*}{ Attitude } & \multirow[b]{2}{*}{ No } & \multicolumn{5}{|c|}{ Response (\%) } \\
\hline & & $\begin{array}{l}\text { Strongly } \\
\text { agree }\end{array}$ & Agree & Uncertain & Disagree & $\begin{array}{l}\text { Strongly } \\
\text { disagree }\end{array}$ \\
\hline More players should use protective eyewear & 193 & $23(20)$ & $34(45)$ & $32(25)$ & $8(7)$ & $2(3)$ \\
\hline Protective eyewear should be made compulsory & 190 & $7(8)$ & $9(9)$ & $26(26)$ & $36(39)$ & $22(18)$ \\
\hline Protective eyewear should be made compulsory for junior players & 192 & $25(18)$ & $31(36)$ & $25(23)$ & $14(13)$ & $5(10)$ \\
\hline I would stop playing squash if protective eyewear were made compulsory & 191 & $5(0)$ & $3(6)$ & $28(23)$ & $38(71)$ & $26(0)$ \\
\hline Eye injuries are a particular problem for squash players ${ }^{\star}$ & 193 & 19 & 38 & 27 & 14 & 2 \\
\hline Protective eyewear is useful for preventing eye injuries during squash ${ }^{\star}$ & 191 & 46 & 48 & 5 & 2 & 0 \\
\hline
\end{tabular}

$\star$ Comparison data from Perth not available. 


\section{Discussion}

This paper presents the results of a survey of 197 squash players, with the majority $(61 \%)$ having played for over ten years, and $76 \%$ playing for more than two hours a week. This represents a reasonable sample of squash players with which to assess attitudes towards protective eyewear, given the hours played in which there was potential exposure to the risk of eye injury. It is also comparable with the only other Australian survey conducted on attitudes towards protective eyewear. ${ }^{13}$

The response rate of $56 \%$ is fairly reasonable given the nature of the survey dissemination. Unfortunately, the reasons for non-response could not be assessed in this study. It is possible that players with negative attitudes towards eye injury and protection may have been less likely to respond to the survey questionnaire.

The self reported incidence of eye injuries in the surveyed players was $15 \%$. This was lower than the figure of $26 \%$ reported by Genovese et $a l .{ }^{13}$ This study did not address the severity or nature of any reported eye injuries. Respondents were simply asked "have you ever had an eye injury whilst playing squash?". Without further definition of the phrase "eye injury", it is possible that some players may have reported an eyebrow laceration, for example, as an eye injury. However, since the rate of self reported eye injuries was less than that reported in other studies, ${ }^{13}$ this is unlikely to be a serious bias in the present study. It is also possible that some community squash players had previously suffered loss of vision or experienced a lack of confidence in returning to play. Consequently, the estimate of injuries in the playing population may be conservative, because people who had retired from active play as a result of previous injuries would not have been included in the sample. ${ }^{13}$

A limitation of this study, was the inability to translate the incidence of eye injury into a rate per playing hours as reported in other studies. ${ }^{38132324}$ This was the result of not collecting accurate information about the precise mean hours of play per week and total playing years for those suffering eye injuries. Consequently comparisons with other studies have not be made.

In this study, a blow from an opponent's racquet was reported to be the most frequent cause of an eye injury (77\%). This is not unexpected since players at community squash centres may have less well developed playing techniques and positioning skills than more senior players. The results of this survey are also consistent with findings from other community based surveys ${ }^{1322} 26$, in that the racquet was also the most frequent cause of injury to other sections of the body.

The $17 \%$ rate of eye injury in competitive players supports the view that even the most competitive players cannot avoid injury. Easterbrook $^{3}$ has suggested that better players experience an increased risk of injury, because they never take their eyes off the ball. He also claims that the novice tends to watch the front wall, and not the ball, and is probably therefore less likely to receive an eye injury. ${ }^{3}$ Loran $^{21}$ sug- gested that the amount of time spent on court may also be a significant factor explaining why competitive players suffer more injuries, in that they spend more time on the squash court and therefore, on an exposure basis alone, are more likely to suffer an injury. This is in contrast with the findings of studies in the United States and the experience of the Victorian Squash Federation that novices tend to play too close to other players and turn around to face the back of the court when the ball is behind them. Furthermore, novices are not necessarily trained in correct follow through techniques, and their poor technique puts them at increased risk of injury.

Despite the obvious risks associated with eye injuries in squash, only $9 \%$ of respondents reported that they wore what they considered to be protective eyewear when playing squash. This again supports the work of Genovese et $a l,{ }^{13}$ who reported that only $10 \%$ of those surveyed wore what they believed to be protective eyewear. Of those wearing protective eyewear, $94 \%$ were competitive players, and this may reflect the increased concern of those at higher levels with injury, particularly since most $(65 \%)$ of those using protective eyewear said that they did so because they did not want to receive an injury.

A significant proportion (35\%) of those who indicated the type of protective eyewear that they used believed that their prescription lenses were a form of protective eyewear. This is an alarming result, given the inherent dangers in wearing such eyewear on the court. ${ }^{3}{ }^{13} 161230-33$ Prescription lenses have been shown to shatter and splinter on impact from either a racquet or ball, with the result that fragments are driven back into the player's eye. ${ }^{34}$ The only eyewear approved by Squash Australia is made of polycarbonate, which will not shatter or splinter on impact and meets the SANZ4066:1992 Standard.

Apart from the Australian/New Zealand safety standards, protective eyewear can be tested against the American (ASTM F803) or Canadian (CSA P408) standards. ${ }^{22}$ Currently, the American standard is the most widely used, and a British BSI standard is being developed. A major disadvantage of the American standard is that it was developed for the hardball version of the game. The international game of squash uses a soft ball, and so the American standard may not necessarily be appropriate for testing the effects of impacts from a "soft" ball. Eyewear that passes the requirements of the Australian/New Zealand standard also meets the frontal impact criterion of the American standard. A joining together of the Australian/New Zealand and American standards could possibly lead to the development of a uniform (international) standard.

Players should be encouraged to wear safe and appropriate protective eyewear that has been shown to be effective. This means that it should meet one of the available safety standards. The advent of a British Standard in 1998 will enable eyewear available in Britain and Europe to be demonstrated to meet a minimum safety standard. 
Easterbrook $^{3}$ stated that players who wore prescription lenses had very little difficulty in wearing eyeguards for squash. He suggested that other players who wear sunglasses can wear protective eyewear around the house for a week to become accustomed to them and thereafter be able to wear them on court with little difficulty.

Most of those deciding not to wear protective equipment believed it was unnecessary. These were predominantly social or casual players. In his study, Loran ${ }^{21}$ also concluded that a high proportion of players consider that the risk of injury while playing without eye protection was remote. Given the risks associated with squash and the importance of maintaining sight, these attitudes need to be modified. Education of players about the potential risks is a major challenge in the promotion of protective eyewear. Another reason given for not wearing protective eyewear was that the players perceived themselves to be experienced and therefore did not need them. This is despite the fact that other studies have found these players to be at more, or at least equivalent, risk. ${ }^{321}$

Despite the lack of use, knowledge about the availability of protective eyewear was quite high, with $60 \%$ of survey respondents stating that it was available at squash centres and clubs. This shows an increased awareness. However, attitudinal change also needs to take place.

This survey showed that more players tended to feel that protective eyewear should be used (57\% agreeing and 10\% disagreeing). However, many (25\%) players remained uncertain about this. This range of responses was similar for other attitudinal responses. The use of compulsory eyewear in juniors was well supported (56\% agreed and 19\% disagreed). Nevertheless, most respondents (39\%) disagreed that protective eyewear should be made compulsory for all players. However, $71 \%$ also stated that they would not stop playing if this regulation came into force. This reflects a positive set of attitudes and supports the possibility of developing regulations with appropriate and positive promotion campaigns.

The risk of eye injury in squash is clearly unacceptably high. The International Federation of Sports Medicine has brought attention to the fact that, while eye injuries in sport are relatively frequent, they are almost completely preventable. ${ }^{27}$ The Victorian Squash Federation has been extremely active in the promotion of protective eyewear and recent activities include the incorporation of protective eyewear within coaching kits used in schoolyard and squash centre coaching clinics. ${ }^{29}$ Similar activities are also being undertaken by the squash bodies in the other Australian states.

In some states of the United States and provinces of Canada a mandatory ruling to use protective eyewear for squash has been made through regional sports bodies. ${ }^{132122}$ As a result the incidence of serious eye injury has decreased significantly. ${ }^{22}{ }^{28}$ Authorities in Australia, the United Kingdom, and Europe have not as yet widely implemented such rulings.
Some steps have been taken towards compulsory wearing in Australia where the national squash body has made it mandatory for compulsory usage of eyewear during doubles matches. From October 1997, all Australian junior championship competitors will be required to wear protective eyewear. This has been extended to compulsory protective eyewear use during all junior tournaments in most states of Australia. There are also moves to make eyewear compulsory for all players in Australia by the year 2000 .

The European Squash Federation has recently voted in favour of mandatory eyewear in all European sanctioned junior tournaments from $1999 .{ }^{22}$ Following these regional initiatives, the World Squash Federation will be voting on a similar regulation during its 1997 meeting. ${ }^{22}$

Increasing the use of protective eyewear and consequently reducing eye injuries will require: the availability of safe, appropriate and standards approved protectors; the education of players of the inherent risks in their sport; the coaching of players in safe techniques, positioning, and use of protective eyewear; and the enforcement of sports regulations to encourage safer play. ${ }^{21}{ }^{29}$ These activities have been key factors in decreasing the incidence of eye injury in the United States and Canada, and should be incorporated into Australian and British attempts to do the same. The ultimate goal therefore is the compulsory wearing of protective eyewear by all squash players when on court. To achieve this we must follow a path similar to that which, after ten years of extensive campaigning, led to the compulsory wearing of bicycle helmets in Victoria. ${ }^{35}$ It is hoped that this will be achieved by the year 2000 and consequently that the incidence of eye injury will be significantly reduced.

The Victorian Squash Federation was funded to undertake this survey by the Department of Human Services, Victoria under the statewide injury prevention strategy "Taking Injury Prevenrward". C F was funded by a PHRDC (Public Health Research and Development Committee) Research Fellowship while employed at the Monash University Accident Research Centre. The seven squash centres and their members and social players are gratefully thanked for their participation in the study. Chantelle Fitzpatrick of the Victorian Squash Federation coordinated the survey.

1 Jones $\mathrm{N}$, Turnbull A. Eye contact and how to avoid it! Squash Player 1991;Mar:33-5.

2 Fong LP. Sports-related eye injuries. Med f Aust 1994;160: $743-50$

3 Easterbrook M. Eye protection in racquet sports. Clin Sports Med 1988;7:253-66.

4 Garrow A. A statistical inquiry into 1000 cases of eye injuries. Br f Ophthalmol 1923;7:65-80.

5 MacEwen CJ. Eye injuries: a prospective survey of 5671 MacEwen CJ. Eye injuries: a prospecti

6 North IM. Ocular hazards of squash. Med $f$ Aust 1973;1:165-6.

7 Ingram DV, Lewkonia I. Ocular hazards of playing squash racquets. Br f Ophthalmol 1973;94:813-15.

8 Barrell GV, Cooper PJ, Elkington AR, et al. Squash ball to eye ball. BMF 1981;283:893-5.

9 Blonstein JL. Eye injuries in sport with particular reference to squash rackets and badminton. Practitioner 1975;215: 208-9.

10 Easterbrook M. Eye injuries in squash: preventable disease. Canadian Medical Association fournal 1978;118:298-305.

11 Easterbrook $M$. Eye injuries in racquet sports: a continuing problem. Canadian Medical Association fournal 1980;123: 268-9.

12 Gregory PTS. Sussex eye hospital sports injuries. $\mathrm{Br} \mathcal{F} \mathrm{Oph}$ thalmol 1986;70:748-50.

13 Genovese MT, Lenzo NP, Lim RK, et al. Eye injuries among pennant squash players and their attitudes towards protective eyewear. Med f A Aust 1990;153:655-8. 
14 Jones NP. Eye injuries in sport: an increasing problem. $\mathrm{Br} \mathcal{F}$ Sports Med 1987;21:168-70.

15 Jones NP. Eye injury in sport. Sports Med 1989;7:163-81.

16 MacEwen CJ. Sports associated eye injury: a casualty department survey. Br f Ophthalmol 1987;71:701-5.

17 Moore MC, Worthley DA. Ocular injuries in squash players. Australian fournals of Ophthalmology 1977;5:46-7.

18 Quere MA, Pietrini P. Eye injuries and squash. Bulletin of Ophthalmological Society of France 1986; 86:1499-1500.

19 Sabiston D. Squash and eye injuries. New Zealand fournal of Sports Medicine 1976;4:3-5.

20 Jones NP. One year of severe eye injuries in sport. Eye 1988; 2:484-7.

21 Loran D. Eye injuries in squash. Optician 1992;Mar:18-19, 21-22,23,26.

22 Bronstein M. Eyes right. Squash Player 1997;Aug:26-29.

23 Clemett RS, Fairhurst SM. Head injuries from squash: a prospective study. $N Z$ Med $\mathcal{F} 1980 ; 92: 1-3$.

24 vinger PF. The eye and sport medicine. In: Duane TD, Jaeger EA, eds. Clinical ophthalmology. Philadelphia: Harper and Row, 1991;5:1-51.

25 Swann PG, Doherty $M$. An eye injury from squash racquets. Australian fournal of Optometry 1980;63:75-7.

26 Locke AS. Squash racquets: a review - deadly or safe? Med $\mathcal{f}$ Aust 1985;143:565-7.
27 International Federation of Sports Medicine. Eye injuries and eye protection in sports. Br f Sports Med 1989;23:

28 Vinger PF. Sports eye injuries: a preventable disease. American Academy of Ophthalmology 1981;88:108-12.

29 Vear P. Injury prevention in squash and racquetball: protective eyewear. In: Injury research and prevention: a text. Monash University Accident Research Centre, 1995: 201-4.

30 David JK. Lenses for sports vision. In: Pizzarello LD, Haik DG, eds. Sports ophthalmology. Springfield, IL: Charles C Thomas, 1987:9-44.

31 Easterbrook $M$. Eye injury in squash and racquetball players: an update. Physician and Sportsmedicine 1982;10:47-57.

32 Anonymous. Eye injuries and eye protection in sports. [Editorial]. Sport Health 1989;7:19-20.

33 Diamond GR, Quinn GE, Pashby TJ, et al. Ophthalmic injuries. Clinical Sports Ophthalmology 1982;1:469-82.

34 Barrell GV, Cooper PJ, MacFayden JM. Eye injuries at squash: who is at most risk? New Zealand fournal of Sports squash: who is at most

35 Cameron MH, Vulcan AP, Finch CF, et al. Mandatory bicycle helmet use following a decade of helmet promotion in Victoria, Australia: an evaluation. Accident Research Centre 1994;26:325-37.

\begin{tabular}{|c|c|c|}
\hline \multicolumn{3}{|c|}{ BASM Merchandise 1998} \\
\hline Ties & $\begin{array}{l}\text { Single motif } \\
\text { Multi motif }\end{array}$ & $\begin{array}{l}£ 6+£ 1.50 \mathrm{p} \& \mathrm{p} \\
£ 6+£ 1.50 \mathrm{p} \& \mathrm{p}\end{array}$ \\
\hline Blazer badge & $\begin{array}{l}\text { Wire - } 4 \text { inches high } \\
\text { Wire }-3 \text { inches high }\end{array}$ & $\begin{array}{l}£ 5+£ 1.50 \mathrm{p} \& \mathrm{p} \\
£ 5+£ 1.50 \mathrm{p} \& \mathrm{p}\end{array}$ \\
\hline \multicolumn{3}{|c|}{ New stock to order } \\
\hline Sweaters & $\begin{array}{l}\text { Lambswool fine knit, V-neck or round } \\
\text { neck with small motif. Machine washable. } \\
\text { State colour and chest size required. }\end{array}$ & $£ 32+£ 3 \mathrm{p} \& \mathrm{p}$ \\
\hline Sweatshirts & $\begin{array}{l}\text { With small motif. } \\
\text { State colour and chest size required. }\end{array}$ & $£ 25+£ 3 \mathrm{p} \& \mathrm{p}$ \\
\hline Polo shirts & $\begin{array}{l}\text { With small motif. } \\
\text { State colour and chest size required. } \\
\text { Some education polo shirts in cream } \\
\text { and grey are also available at the same pric }\end{array}$ & $£ 23+£ 3 \mathrm{p} \& \mathrm{p}$ \\
\hline $\begin{array}{l}\text { Send orders tc } \\
\text { Birch Lea, } 67 \\
\text { UK. (Tel: } 017\end{array}$ & $\begin{array}{l}\text { hn H Clegg JP BSc LDS RCS Eng, Hon Se } \\
\text { ingfield Lane, Eccleston, St Helens, Mersey } \\
\text { 28198) }\end{array}$ & $\begin{array}{l}\text { ecretary, } \\
\text { yside WA10 5HB, }\end{array}$ \\
\hline
\end{tabular}

